\author{
Military Technical College \\ Kobry El-Kobbah, \\ Cairo, Egypt
}

14th International Conference on

Applied Mechanics and

Mechanical Engineering.

\title{
Solid-state diffusion enhancement of liquid phase joints between austenitic stainless steel alloy and magnesium alloy
}

\author{
By \\ Waled Mohamed Elthalabawy*, Tahir Irfan Khan**
}

\begin{abstract}
:
The drive to reduce vehicle emissions and fuel consumption, yet maintain strength has led to the increase in use of austenitic stainless steels and magnesium alloys in the transport industry. Therefore, the bonding together of these dissimilar alloys is of critical importance. In this study, a solid-state diffusion bonding of $316 \mathrm{~L}$ to $\mathrm{Ni}$ interlayer at $900^{\circ} \mathrm{C}$ preceded a transient liquid phase bonding between $\mathrm{AZ31}$ and the $\mathrm{Ni}$ interlayer at $510^{\circ} \mathrm{C}$. The results showed that, during the liquid phase bonding, the bonding time controlled the isothermal solidification stage and resulted in a metallurgical bond. A combination of solid-state reaction at the 316 L steel-Ni interface and eutectic liquid formation at the AZ31/ Ni gained a 17\% increase in the joint shear strength compared to joints produced without the solid-state diffusion-bonding step.
\end{abstract}

\section{Keywords:}

Magnesium alloy, Stainless steel, Bonding, Microstructure, intermetallics 
* Egyptian Armed Forces \& University of Calgary, Alberta, Canada

** University of Calgary, Alberta, Canada

\section{Introduction:}

The good corrosion resistance, formability and strength make stainless steel 316 L popular for a diverse range of applications. The high strain rate sensitivity during deformation and hence crashworthiness make this alloy suitable for use in the transportation industry [1-3]. When, this austenitic steel is subjected to high strain values as in the case of a crash situation, the work hardening effect increases the strength of the steel to 4 times that of its original value [1, 4].

On the other hand, the low density of wrought magnesium alloy AZ31 provides an alternative material to replace heavy steel or aluminum components. Introducing lighter components in the automotive and aerospace industries gives a weight reduction which provides cost saving associated with fuel consumption, [5-7]. Recently, many automotive and aerospace components are produced using magnesium alloys [7, 8] and austenitic stainless steels [2, 9, 10]. However, the joining together of these dissimilar alloys still presents a challenge and this is attributed to considerable differences in their physical and metallurgical properties [11-13]. The transient liquid phase (TLP) bonding process provides a method to overcome these differences in physical and metallurgical characteristics of the alloys. The TLP bonding process uses interlayers in the form of metal foils or electroplated sputter coatings that form a eutectic with the alloys being joined.

When the entire assembly is heated up to the bonding temperature, the interlayer either melts or forms a eutectic with the base metal and on holding at the bonding temperature a joint forms by isothermal solidification, [14, 15].

In this study, a double stage bonding technique was developed to join AZ31 to the $316 \mathrm{~L}$ steel. The effect of bonding parameters on microstructural developments and joint strength properties was examined.

\section{Experimental Procedure:}

The material used in this study was a commercial AZ31 has a composition (in wt\%) of $3 \% A l$, $1 \% \mathrm{Zn}$ and $96 \% \mathrm{Mg}$. The alloy samples were cut from an extruded $10 \mathrm{~mm}$ diameter rod to $5 \mathrm{~mm}$ thick disks and then prepared on SiC paper to 800 grit surface finish and cleaned with methanol.

However, $1 \mathrm{~cm}^{3}$ samples of the $316 \mathrm{~L}$ austenitic steel were cut from a $10 \mathrm{~mm}$ thick rolled sheet has a composition (in wt \%) of $18 \% \mathrm{Cr}, 11 \% \mathrm{Ni}, 2 \% \mathrm{Mo}, 1.8 \% \mathrm{Mn}, 0.03 \% \mathrm{C}, 1.5 \% \mathrm{Si}$ and $\mathrm{Fe}-\mathrm{Bal}$. The 316L steel samples were prepared on SiC paper to 800 grit surface finish, ultrasonically cleaned in acetone bath. A $20 \mu \mathrm{m}$ thick foils interlayer of pure Ni was used as eutectic liquid phase former.

For TLP bonding, the Ni foil was placed between the AZ31 and $316 \mathrm{~L}$ bonding surfaces in the form of a sandwich. Prior to TLP bonding to AZ31, the Ni interlayer surfaces were polished using $1 \mu \mathrm{m}$ diamond paste and cleaned with acetone and then solid-state bonded to $316 \mathrm{~L}$ steel. The $316 \mathrm{~L} / \mathrm{Ni}$ solid state diffusion bond was achieved at $900^{\circ} \mathrm{C}$ for 15 minutes and under $2 \mathrm{MPa}$ bonding pressure [16, 17]. 
According to the Mg-Ni binary equilibrium phase diagram in Fig. 1, [18] samples were TLP bonded at $510^{\circ} \mathrm{C}$ for time intervals from 3 to 60 minutes and under a $0.2 \mathrm{MPa}$ bonding pressure. This temperature was selected close to the lowest eutectic reaction in order to achieve a bond with minimum degradation of the magnesium alloy AZ31. Both solid state diffusion and TLP joining were performed in a chamber under a vacuum pressure of $3 \times 10^{-4}$ torr and a heating rate of $0.8^{\circ} \mathrm{Cs}^{-1}$ was achieved using induction heating coil.

The temperature was monitored using a K-type thermocouple inserted close to the bond interface. However, the bonding pressure in either solid state diffusion or TLP joining was maintained using the concept of dead weight in order to hold the joint assembly and enhance surface-to-surface contact.

For metallographic examination, the bonded samples were cut transversely through the joint region, mounted in bakelite and polished using diamond suspension down to a $3 \mu \mathrm{m}$ finish. Microstructural developments across the joint region were examined using light microscopy and scanning electron microscopy (Jeol JXA-8200) with compositional analysis across the joint monitored using wavelength dispersive spectroscopy (WDS).

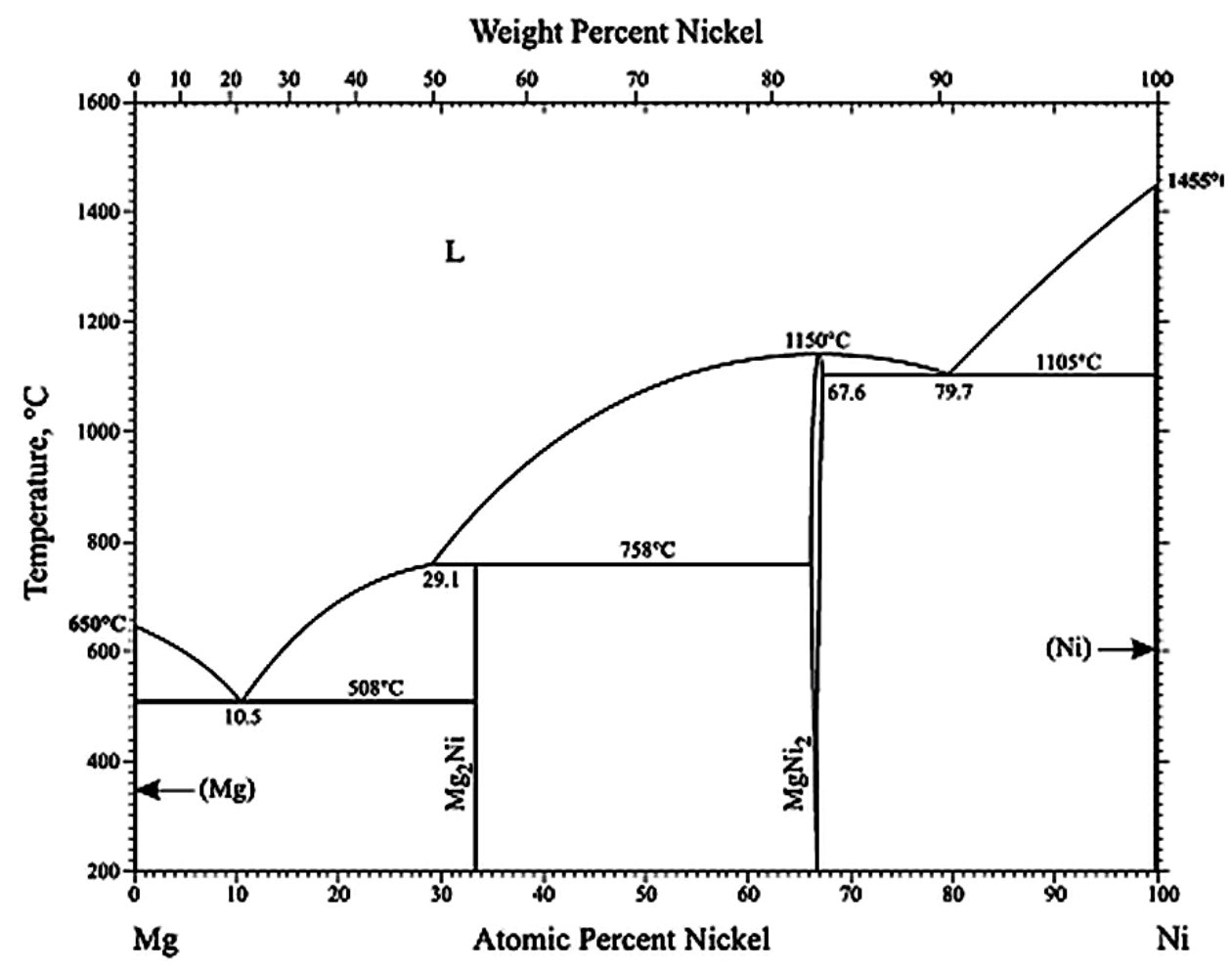

Figure (1): Mg-Ni Binary phase diagram

\section{Results and discussions:}

\subsection{Direct AZ31/Ni/316L TLP bonding}

When applying the direct TLP bonding technique, the experimental results showed that, $\mathrm{AZ31} / \mathrm{Ni} / 316 \mathrm{~L}$ sandwich passes through a solid-state diffusion at $\mathrm{AZ31} / \mathrm{Ni}$ interface that leads to liquid eutectic phase formation and interlayer dissolution. The further change in the liquid phase composition causes the formation of the solid joint by isothermal solidification. 
The SEM micrograph in Fig. 2a illustrates the microstructural changes that took place at the $A Z 31 / \mathrm{Ni}$ interface when heating the $\mathrm{AZ31} / \mathrm{Ni} / 316 \mathrm{~L}$ sandwich up to $510^{\circ} \mathrm{C}$ and holding it for 3 minutes. A reaction layer (L1) and an intermetallic blocky phase were formed due to $\mathrm{Mg}-\mathrm{Ni}$ interdiffusion. By considering the diffusivity of $\mathrm{Mg}$ in $\mathrm{Ni}$ $\left(D^{\circ}{ }_{\mathrm{Mg}-\mathrm{Ni}}=2.23 \times 10^{-9} \mathrm{~m}^{2} / \mathrm{s}\right)$ as a double that of $\mathrm{Ni}$ in $\mathrm{Mg}\left(\mathrm{D}^{\circ} \mathrm{Ni- \textrm {Mg }}=1.2 \times 10^{-9} \mathrm{~m}^{2} / \mathrm{s}\right)$, it can be concluded that $\mathrm{Mg}$ is the dominant element in forming these reaction layer [19].

The WDS analysis showed that the ternary intermetallic phase has a composition of approximately $52 \% \mathrm{Ni}, 37 \% \mathrm{Mg}$ and $9 \% \mathrm{Al}$.

Orimo et al, studied the crystalline forming abilities of the alloys $\left(\mathrm{Mg}_{1-\mathrm{x}} \mathrm{Al} \times \mathrm{x}\right) \mathrm{Ni}$ using mechanical alloying of $\mathrm{Mg}$-rich compositions ranging from $\mathrm{x}=0$ to $\mathrm{x}=0.5$. His work showed that $a$ crystalline phase (B2) was firstly found to be formed in the alloys with $x=0.3,0.4$ and 0.5 , even in the as-alloyed state. This crystalline phase was thermally stable, and was able to interstitially dissolve hydrogen atoms without any structural transformation, [20].

When comparing Orimo results to the obtained ternary intermetallic phase we can conclude that the solid-state diffusion that took place between pure $\mathrm{Ni}$ interlayer and the (Mg-3Al-1Zn) alloy during the heating and holding intervals resulted in a formation of the (B2) phase. This reaction left behind a fine $\mathrm{Mg}_{2} \mathrm{Ni}$ reaction layer (L1) and a pure $\mathrm{Mg}$ then layer that formed due to Al depletion.

On the other hand, the detection of the lamellar eutectic structure shows that the Ni interlayer starts melting after 3 minutes of holding time where the liquid eutectic phase starts to form. The liquid phase formation was achieved due to solid-state reaction that took place between the reaction layer $\left(\mathrm{Mg}_{2} \mathrm{Ni}\right)$ and the pure magnesium following the right to left direction of the eutectic equation (1).

$$
\mathrm{L}_{(23.5 \% N i)} \stackrel{508^{\circ} \mathrm{C}}{\longrightarrow} M g_{2} N i_{(54.7 \% N i)}+M g_{(0 \% N i)} \ldots \ldots \ldots \ldots . .(1)
$$

When the bonding time was increased to 10 minutes, the eutectic liquid phase spread over the contact surfaces, increased the contact area and enhanced diffusion of $\mathrm{Mg}-\mathrm{Ni}$ interdiffusion. This effect generated more eutectic liquid phase and accelerated the dissolution of the interlayer where no pure Ni foil remain at the interface as shown in Fig. $2 \mathrm{~b}$. The generated eutectic phase during both eutectic formation and interlayer dissolution was solidified athermally during the cooling interval.

When the bonding time was increased, the isothermal solidification took place due to a change in the liquid phase composition. The $\mathrm{Mg}$ diffusion into and $\mathrm{Ni}$ segregation out of the liquid layer results in a change in the composition of the joint and leads to the start of isothermal solidification [21]. The effect of increasing the bonding time up to 20, 30 and 60 minutes was illustrated by Figs. $2 \mathrm{c}, \mathrm{d}$ and e respectively. By increasing the bonding time, the width of the eutectic phase witnessed a remarkable decreased while the solid/liquid interface pushed the (B2) phase towards the 316L interface. On the other hand, more intergranular precipitations of the second phase (B2) were observed within the joint interface and close to the AZ31 base metal. This effect continued until no eutectic phase was detected at the end of the isothermal solidification stage. 

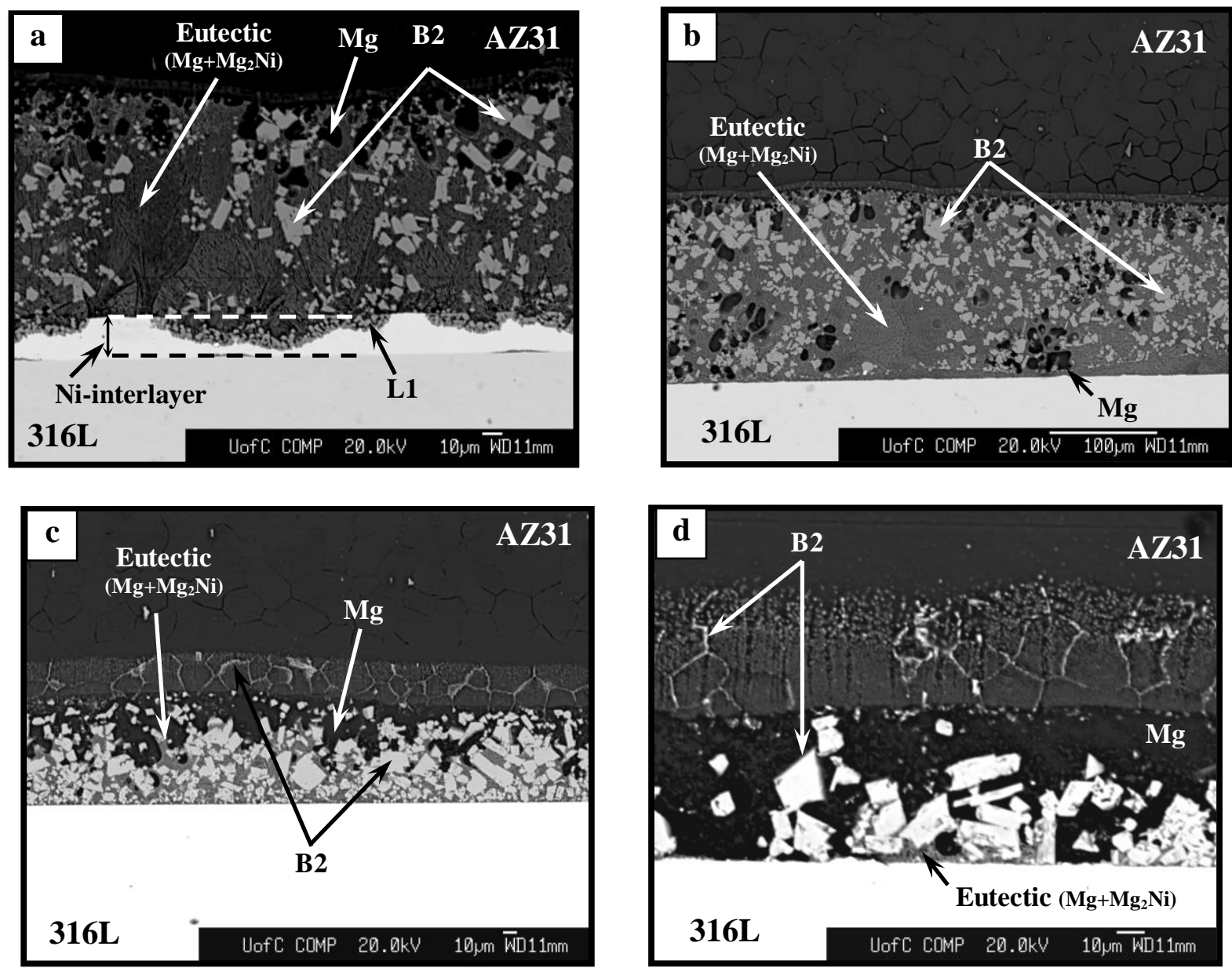

Figure (2): SEM micrograph of 316L/Ni/AZ31 interface bonded at $5100 \mathrm{C}$ for: $3 \mathrm{~min}$, b) $10 \mathrm{~min}, \mathrm{c}) 20 \mathrm{~min}$ and d) $60 \mathrm{~min}$

\subsection{Mechanical evaluation of AZ31/Ni/316L TLP joints}

Fig. 3 illustrates the effect of the bonding time on the lap shear strength of different joints using $\mathrm{Ni}$ interlayers. The joint shear strengths showed a gradual increase in the bond strength until it reached $45.9 \mathrm{MPa}$ when the holding time was set at 20 minutes. This effect can be attributed to the change in the interface homogeneity between the intermetallic phase $\left(\mathrm{B}_{2}\right)$ and the $\left(\mathrm{Mg}+\mathrm{Mg}_{2} \mathrm{Ni}\right)$ eutectic phase with changing holding time. This homogeneity reached its maximum when the hold time reached 20 minutes where the eutectic phase was not fully isothermally solidified, as shown in Fig. 2c.

A further increase in the bonding time to 60 minutes resulted in a significant decrease in the bond shear strength and this was attributed to the absence of the eutectic phase and also to grain coarsening and intergranular precipitation of intermetallics around the AZ31 grains located close to the bond interface. 


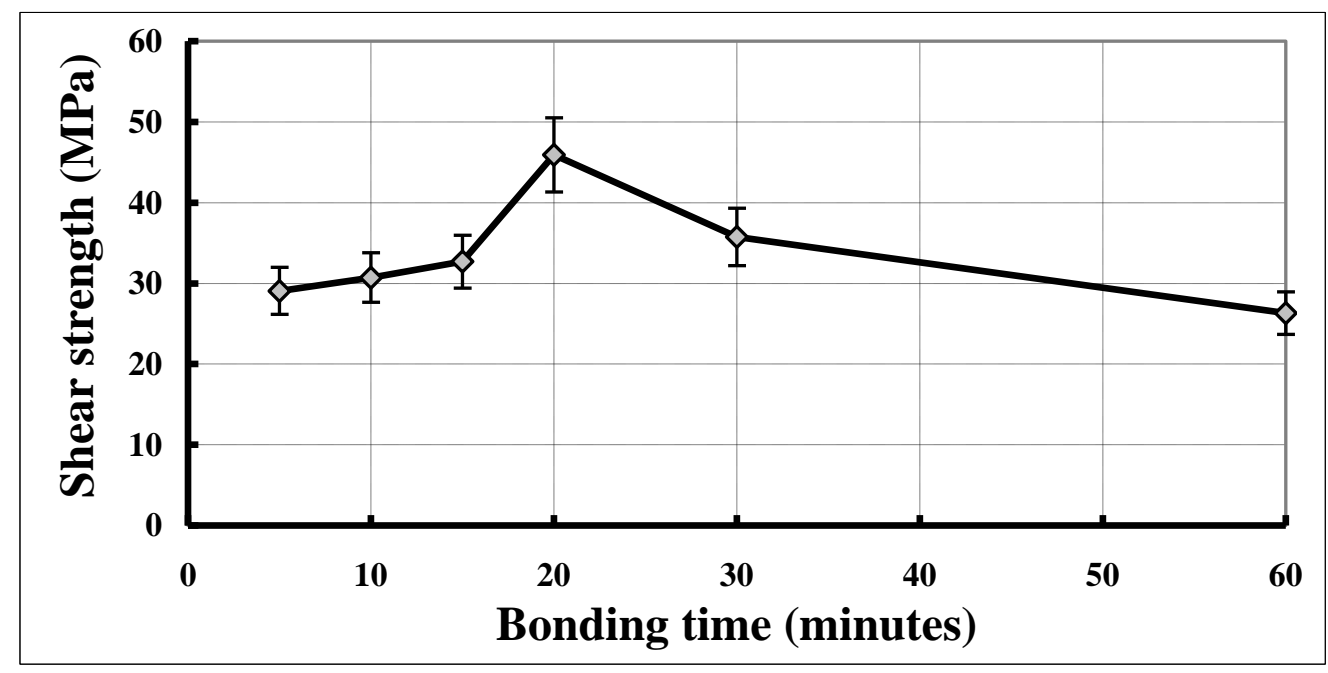

Figure (3): Effect of bonding time on the joint shear strength

Fig. 4 shows the SEM micrograph and the XRD analyses that were taken for the fracture surface on the $316 \mathrm{~L}$ steel side for a TLP joint made at $510^{\circ} \mathrm{C}$ for 20 minutes. The lamellar structure and the intermetallics that were detected on the fracture surface indicated that the fracture took place at the joint but away from the $316 \mathrm{~L}$ steel interface. This result was confirmed by the XRD results where the peaks correspond to the eutectic products $\left(\mathrm{Mg}+\mathrm{Mg}{ }_{2} \mathrm{Ni}\right)$. Moreover, the detection of the minor phase $\left(\mathrm{Fe}_{0.6} \mathrm{Ni}_{0.36}\right)$ within the fracture surface confirmed that, an interdiffusion of $\mathrm{Fe}$ and $\mathrm{Ni}$ took place during the bonding process and resulted in a limited reaction product at the $316 \mathrm{~L}$ interface. However, the line analyses across the bond interfaces for 20 minutes of holding times failed to show a defined reaction layer across the 316L/Ni interface (see Fig. 5).
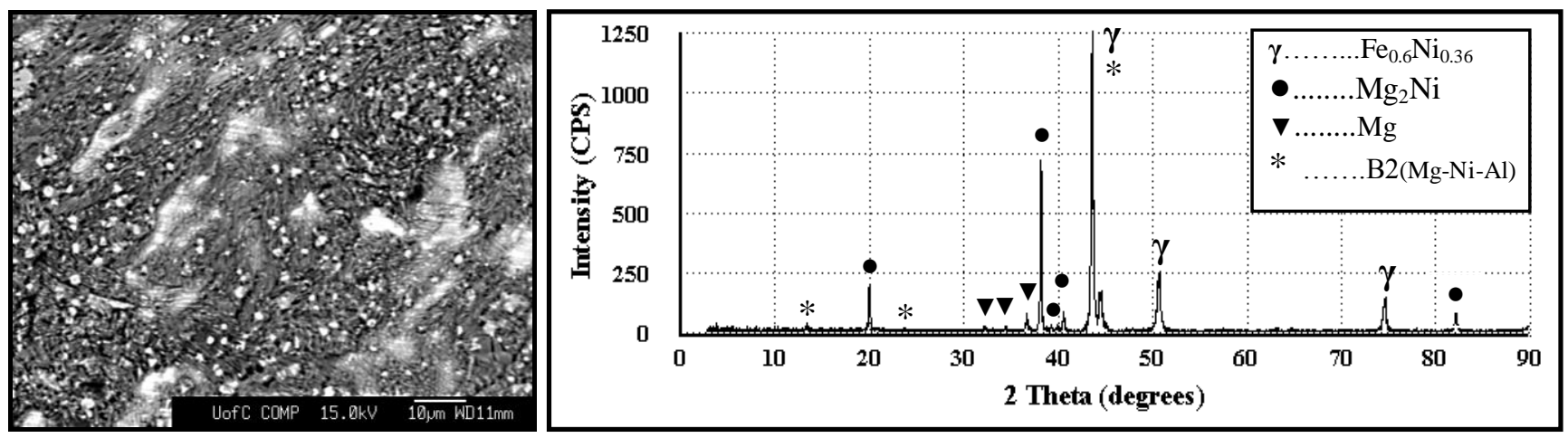

Figure (4): Fracture surface and XRD analyses of 316L/Ni/AZ31 taken from the $316 \mathrm{~L}$ interface. 

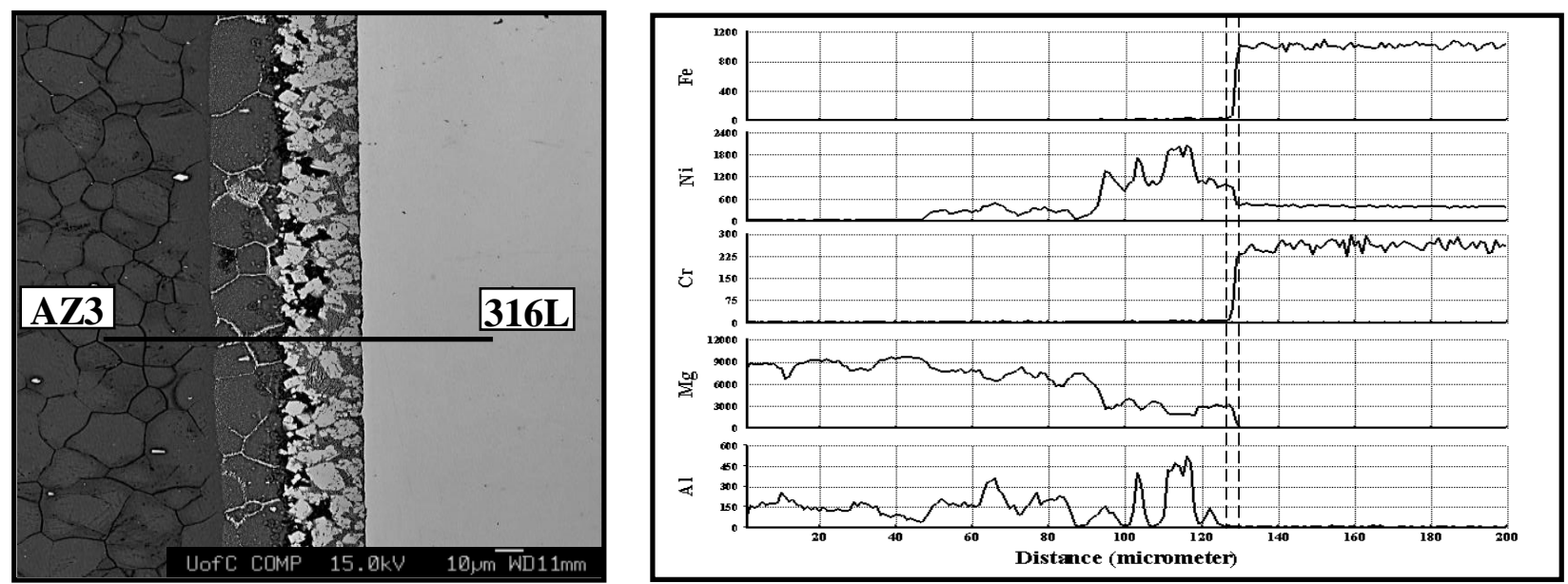

Figure (5): Line analyses across a 316L/Ni/AZ31 bond interface after 20 min bonding

\subsection{Solid state diffusion enhancement of 316L/Ni interface}

Fig. 6 illustrates an SEM micrograph of the 316L/Ni interface after solid state difusion bonding. The absence of interface voids indicated that the applied pressure and surface finish provide good surface-to-surface contact and achieved an excellent solid state bonds at the selected bonding conditions. Moreover, the WDS line analyses across the bond showed that the $316 \mathrm{~L} / \mathrm{Ni}$ interface witnessed a formation of $\mathrm{Ni} / \mathrm{Fe}$ reaction layer. The $\mathrm{Ni}$ and $\mathrm{Fe}$ concenterations changed gradually along this layer until it reached values similar to those in the base metal.
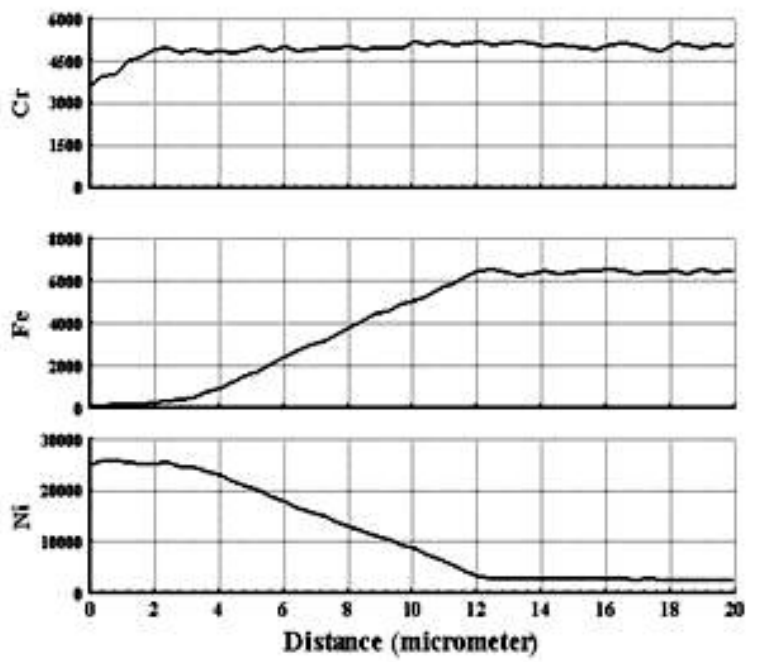

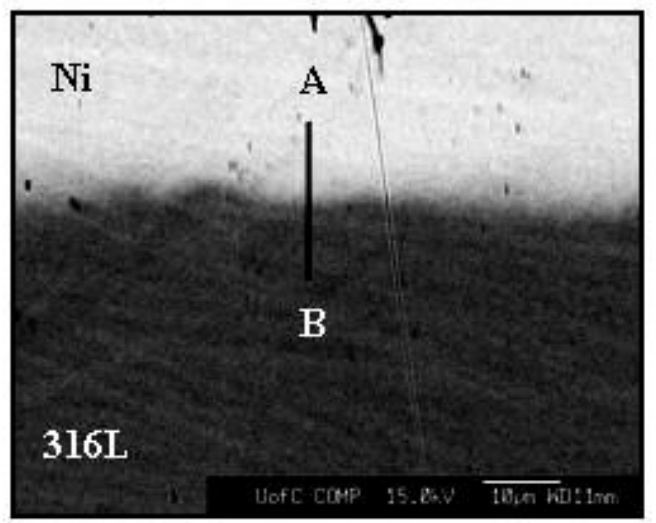

Figure (6): WDS line analyses across the 316L/Ni reaction layer along line A_B.

\subsection{TLP bonding of $316 \mathrm{~L} / \mathrm{Ni}$ solid state joint to AZ31 alloy}

The 316L/Ni solid state joint was bonded to the AZ31 magnesium base metal using transient liquid phase (TLP) bonding at $510^{\circ} \mathrm{C}$ for 20 minutes. The SEM micrograph and the line 
analysis across the 316L/Ni/AZ31 enhanced joint interface shown by Fig. 7 illustrated that a eutectic liquid phase was generated according to the mechanism explained earlier. An intermetallic phase $\left(\mathrm{B}_{2}\right)$ and Ni-Mg eutectic products were still detected.

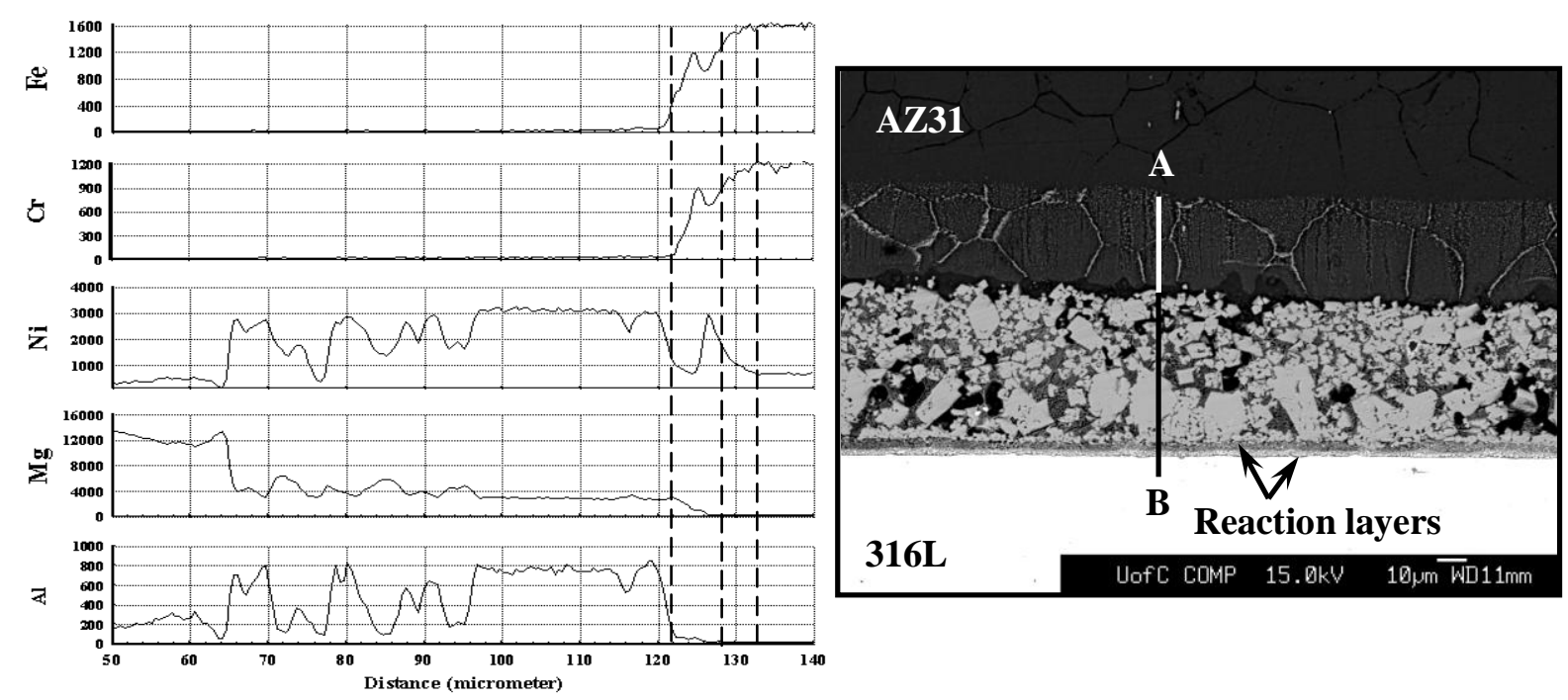

Figure (7): SEM micrograph and line analyses across the 316L/Ni/AZ31 double stage bounded interface along line $A \_B$

However, remarkable reaction layer was continuously observed along the bond interface toward the $316 \mathrm{~L}$ base metal surface. The line spectrum of this phase shown by Fig. 7 showed that this reaction layer consists of two different regions with distinct differences in composition. The region located close to the AZ31/Ni eutectic reaction consisted of the elements Fe-Cr-Ni-Mg-Al while the one located at the Ni/316L interface was reach in Fe-Ni$\mathrm{Cr}$ and there was a change in composition until the 316L base metal composition was attained close to the 316 L steel. By considering the data given in the solid state bonding, it can be concluded that, by increasing the $\mathrm{Ni}$ content at the $316 \mathrm{~L}$ steel surface, the $\mathrm{Mg}$ was able to diffuse and react with the $\mathrm{Fe}-\mathrm{Ni}$ reaction layer during the eutectic reaction and successfully achieve a thicker reaction layer composed of Fe-Cr-Ni-Mg-Al.

The shear test of the double stage bonded joints showed that, when single and double stage joints were bonded at $510^{\circ} \mathrm{C}$ for 20 minutes, the bond strength increased to $53.5 \mathrm{MPa}$ for the double stage one. This $17 \%$ increase in the bond shear strength can be attributed to the formation of the reaction layers toward the $316 \mathrm{~L}$ base metal. The results suggest that the formation of an $\mathrm{Fe}-\mathrm{Cr}-\mathrm{Ni}-\mathrm{Mg}$-Al rich reaction layer at the joint provides a metallurgical bond, and $\mathrm{Ni}$ diffusion at the Ni/316L interface enhances the mechanical strength at the joint, the existence of the intermetallics within the bond interface still impairing the joint mechanical properties.

\section{Conclusions:}

Transient liquid phase joining of austenitic stainless steel alloy $316 \mathrm{~L}$ to magnesium alloy AZ31 was successfully achieved using a pure nickel interlayer. The joint shear strength showed a gradual increase in strength with increasing bonding time reaching a maximum value of $45.9 \mathrm{MPa}$ at a holding time of 20 minutes. However, further increase in the holding time deteriorates the joint strength. The use of a double stage bonding technique increased 
the joint shear strength to a value of $53.5 \mathrm{MPa}$ representing a $17 \%$ increase in joint strength. Joint formation in this case was attributed to a solid state reaction at the $316 \mathrm{~L}$ steel/Ni interface and a eutectic formation at the $\mathrm{AZ31} / \mathrm{Ni}$ interface followed by isothermal solidification.

\section{References:}

[1] F. Friesen, D. Schwarz, and P. J. Cunat, "Application of stainless steel in vehicle crash structures," VDI Berichte, pp. 231-246, 2002.

[2] J. B. Emmons and J. Douthett, "Automotive frames of stainless steel," Advanced Materials \& Processes, vol. 150, pp. 23-25, 1996.

[3] K. Young Hwan, K. Kwang Yuk, and L. Yong Deuk, "Nitrogen-alloyed, metastable austenitic stainless steel for automotive structural applications," Materials and Manufacturing Processes, vol. 19, pp. 51-9, 2004.

[4] M. O. Speidel and H. J. C. Speidel, "Austenitic stainless steels of high strength and ductility," Zeitschrift fuer Metallkunde/Materials Research and Advanced Techniques, vol. 95, pp. 596-600, 2004.

[5] M. K. Kulekci, "Magnesium and its alloys applications in automotive industry," International Journal of Advanced Manufacturing Technology, vol. 39, pp. 851-865, 2008.

[6] A. A. Luo, "Magnesium: Current and potential automotive applications," JOM, vol. 54, pp. 42-48, 2002.

[7] F. C. Campbell, Manufacturing Technology for Aerospace Structural Materials, First edition ed. UK: Elsevier Ltd., 2006.

[8] J. Goken, J. Bohlen, N. Hort, D. Letzig, and K. U. Kainer, "New development in magnesium technology for light weight structures in transportation industries," Materials Science Forum, vol. 426-432, pp. 153-60, 2003.

[9] T. MacNew, "More emphasis on stainless steel for passenger car components," Automotive Industries, vol. 114, pp. 52-53, 1956.

[10] E. Ratte, S. Leonhardt, W. Bleck, M. Franzen, and P. Urban, "Energy absorption behaviour of austenitic and duplex stainless steels in a crash box geometry," Steel Research International, vol. 77, pp. 692-697, 2006.

[11] Z. Sun and J. C. Ion, "Laser welding of dissimilar metal combinations," Journal of Materials Science, vol. 30, pp. 4205-14, 1995.

[12] Z. Sun and R. Karppi, "Application of electron beam welding for the joining of dissimilar metals: an overview," Journal of Materials Processing Technology, vol. 59, pp. 257267, 1996.

[13] Y. Abe, T. Watanabe, H. Tanabe, and K. Kagiya, "Dissimilar metal joining of magnesium alloy to steel by FSW," Stafa-Zuerich, Switzerland, 2006, pp. 393-7.

[14] W. F. Gale and D. A. Butts, "Transient liquid phase bonding," Science and Technology of Welding and Joining, vol. 9, p. 17, 2004.

[15] W. D. MacDonald and T. W. Eagar, "Transient Liquid Phase Bonding," Annual Review of Materials Science, vol. 22, pp. 23-46, 1992

[16] S. Kundu and S. Chatterjee, "Characterization of diffusion bonded joint between titanium and 304 stainless steel using a Ni interlayer," Materials Characterization, vol. 59, pp. 631-637, 2008. 
[17] S. Chatterjee and S. Kundu, "Interfacial microstructure and mechanical properties of diffusion-bonded titanium-stainless steel joints using a nickel interlayer," Materials Science \&amp; Engineering A (Structural Materials: Properties, Microstructure and Processing), vol. 425, pp. 107-13, 2006.

[18] H. Baker, ASM: Alloy Phase Diagrams vol. 3, 1992.

[19] O. Madelung, Numerical data and functional relationships in science and technology, Diffusion in metals and alloys vol. 26 Springer-Verlag Berlin Heidelberg, 1990.

[20] S. Orimo, K. Ikeda, and H. Fujii, "B2-phase formation and hydriding properties of (Mg1xAlx)Ni (x=0 0.5)," Journal of Alloys and Compounds, vol. 266, pp. 1-3, 1998.

[21] I. Tuah-Poku, M. Dollar, and T. B. Massalski, "Study of the transient liquid phase bonding process applied to a $\mathrm{Ag} / \mathrm{Cu} / \mathrm{Ag}$ sandwich joint," Metallurgical Transactions $A$ (Physical Metallurgy and Materials Science), vol. 19A, pp. 675-686, 1988. 